\section{Derecho y medicina}

Fernando Cano-Valle

Academia Nacional de Medicina de México, Ciudad de México, México
Georg Jellinek, quien nació en Leipzig en 1851 y murió en Heidelberg en 1911 y cuya formación incluye estudios de derecho, filosofía, geografía e historia del arte, expresaba que: ${ }^{1}$

...La forma dogmática de las normas jurídicas solo puede
ser explicada mediante el arte del jurista, arte que consiste
en abstraer de los fenómenos jurídicos normas, y en deducir
las consecuencias que estos implican. La dogmática del
derecho es irremplazable, pero el uso exclusivo de la misma
es insuficiente para abarcar los aspectos múltiples de la vida
del Estado, de aquí que el investigador necesite a las otras
disciplinas.

Sin duda, Jellinek se inspiró en John Locke (1632-1704), médico británico representante del empirismo inglés, quien sentó los principios básicos del constitucionalismo liberal.

Prominentes juristas mexicanos a lo largo de los años así han comprendido la relación entre derecho y medicina. El doctor Mario de la Cueva - destacado jurista, médico y rector de la Universidad Nacional Autónoma de México con vocación democráticatambién se interesó en el pensamiento académico de John Locke. Alguna vez expresó que "el Estado y el derecho son creaciones de la vida real", en el sentido que el ordenamiento jurídico regirá la conducta de los hombres. Invitó a juristas contemporáneos a construir desde el derecho una mejor salud de la sociedad mexicana por parte del Estado mexicano. Jorge Carpizo señalaba que "el Estado principia donde la democracia termina". Sergio García Ramírez, Héctor Fix Zamudio, Fix Fierro y Diego Valadés, entre otros distinguidos juristas, han realizado importantes aportaciones a la sociedad mexicana y a la salud, en forma enfática desde el ámbito académico.

En particular, la Academia Nacional de Medicina de México se ha visto enriquecida con la incorporación al seno de esta institución del ministro José Ramón Cossío Díaz, cuyo enfoque interdisciplinario de corte democrático social sin duda continuará siendo un formidable pilar para que la Academia incida más en mejores leyes en torno a la salud. Requerimos publicar, y publicar en la intersección entre el derecho y la medicina, más aún cuando contamos con una revista oficial, que revitalizada con gran contenido social será una herramienta poderosa para analizar los cambios que se vislumbran.

Al facultarse al Congreso a legislar en materia de salubridad, el andamiaje normativo dispone de un régimen de coordinación entre autoridades de los distintos niveles de gobierno con base en la ley marco, es decir, la Ley General de Salud. El gran cúmulo de normativas implica un gran cambio en el sistema de salud en México; exige que el Estado impida abusar de los derechos humanos y plantea una conducta positiva que asegure el derecho a la salud. Es pertinente mencionar que la salud en la actualidad se encuentra sobre regulada, lo que incide negativamente en la prestación de los servicios.

A finales del mes de noviembre de 2018 terminó la gestión de la mesa directiva de la Academia Nacional de Medicina de México correspondiente al periodo 2017-2018. Dos años intensos de avance sostenido y entrega total del presidente, doctor Armando Mansilla Olivares, y el espléndido resultado de todos los directivos de la institución permitirán a la mesa directiva entrante un impulso de fortalecimiento hacia un cambio cualitativo en una ola de renovación de las políticas de salud.

La nueva mesa directiva está presidida por una científica notable. Por vez primera en 155 años de vida, en la Academia estará presente la mujer mexicana en un primer plano de gran significado, la doctora Teresita Corona Vázquez, acompañada por colaboradores de nuevas generaciones que abren grandes expectativas. Ellos estarán en consonancia
Fecha de recepción: 14-12-2018

Fecha de aceptación: 17-12-2018 DOI: 10.24875/GMM.18004929
Gac Med Mex. 2019;155:1-2

Disponible en PubMed www.gacetamedicademexico.com 
con la Organización Mundial de la Salud y la Organización Panamericana de la Salud, en un sistema de salud caracterizado por su segmentación tanto en el financiamiento como en el acceso a los servicios, con un amplio sector privado de servicios de salud que requiere regulación.

La salud enfrenta actualmente problemas demográficos, político-administrativos, financieros y científico-tecnológicos, que señalan la necesidad de que el Estado mexicano asuma el desafío de modificar su modus operandi con el propósito de actuar con mayor eficacia, eficiencia, congruencia y transparencia en una compleja realidad. ${ }^{2}$

En esta nueva etapa, la Academia Nacional de Medicina de México se va a encontrar con las insuficiencias estructurales en la administración de servicios fragmentados, y el costo que esto representa, que no tienen paralelo y cuyo crecimiento ha sido exponencial durante los últimos 30 años, con la consecuencia de una morbilidad crónica creciente, del repunte de los procesos infecciosos, del incremento de las adiciones en la población y de las enfermedades mentales que permanecen sin un abordaje integral eficiente.

La agenda para el cambio requiere un rediseño fundamental, capaz de plantear los escenarios con anticipada claridad y con ello evitar enfrentar tardíamente el problema. No hay duda de que el primer reto que debe enfrentar nuestro sistema de salud es lograr la equidad entre los ciudadanos, resolviendo los rezagos acumulados y la desigualdad inaceptable. La pobreza es privación de capacidades; los indicadores de salud son deficientes en los más pobres y, paradójicamente, se invierte o gasta más en el sector privado.
Requerimos que en el sistema mexicano de salud, los especialistas en salud, en particular los médicos, cobren una nueva centralidad. El médico es el garante real del derecho humano a la salud, por lo que se le debe dotar de todas las herramientas y medios para hacer posible esa labor. ${ }^{3}$

A la par de buscar una cobertura universal de los servicios de salud, también es importante separarlos claramente de otros servicios de seguridad y desarrollo sociales y terminar con la dispersión de los recursos que se les destina. Si bien la salud está íntimamente vinculada con cuestiones de seguridad social, como las pensiones y otros temas de desarrollo social, en la actual distribución de recursos el tema de salud no está concentrado, lo que ocasiona ineficiencia.

Diego Valadés ha señalado que existe un principio según el cual "la ignorancia de la ley no exime de su cumplimiento". De esta manera nadie pude alegar que no cumplió con una disposición por el hecho de no conocerla. Sin embargo, sucede que, al contrario, muchas veces hay derechos que no se ejercen porque no se les conoce. Es menester la participación de la Academia Nacional de Medicina de México para hacer énfasis en que el derecho a la salud es un derecho humano impostergable.

\section{Bibliografía}

1. Jellinek G. La Declaración de los Derechos del Hombre y del Ciudadano. España. Comares; 2009. p. 10.

2. Salazar-Ugarte P, Oropeza-García A, Romero-Tellaeche JA, editores. La responsabilidad el porvenir. Tomo I. México: El Colegio de México, Instituto de Investigaciones Jurídicas UNAM, Instituto para el Desarrollo Industrial y el Crecimiento Económico; 2018. p. 457.

3. Mansilla-Olivares A, Cano-Valle F, Treviño-Becerra A, et al. Declaratoria de la Academia Nacional de Medicina de México. El futuro de la seguridad social y la asistencia médica en México. México: Academia Nacional d Medicina de México; 2018. p. 9 